\title{
John D. Lyons, French literature. A very short introduction
}

\section{Orlando Bonserio}

\section{Q OpenEdition}

1 Journals

\section{Edizione digitale}

URL: http://journals.openedition.org/studifrancesi/6493

DOI: 10.4000/studifrancesi.6493

ISSN: 2421-5856

\section{Editore}

Rosenberg \& Sellier

\section{Edizione cartacea}

Data di pubblicazione: 1 novembre 2010

Paginazione: 610

ISSN: 0039-2944

\section{Notizia bibliografica digitale}

Orlando Bonserio, «John D. Lyons, French literature. A very short introduction», Studi Francesi [Online], 162 (LIV | III) | 2010, online dal 30 novembre 2015, consultato il 11 janvier 2021. URL: http:// journals.openedition.org/studifrancesi/6493 ; DOI: https://doi.org/10.4000/studifrancesi.6493

Questo documento è stato generato automaticamente il 11 janvier 2021.

\section{(c) (i) (9)}

Studi Francesi è distribuita con Licenza Creative Commons Attribuzione - Non commerciale - Non opere derivate 4.0 Internazionale. 


\title{
John D. Lyons, French literature. A very short introduction
}

\author{
Orlando Bonserio
}

\section{NOTIZIA}

JOHN D. LYONS, French literature. A very short introduction, New York, Oxford University Press, 2010, pp. 137.

1 Le Very Short Introductions sono una interessante collana della Oxford University Press iniziata nel 1995, e giunta alla pubblicazione di oltre 200 titoli, che riguardano e presentano quasi tutto lo scibile: i temi sono storici, filosofici, letterari, religiosi, geografici, fisici, politici, sociali, psicologici, ecc. Insomma, quasi 300 capitoli di una potenziale enciclopedia. E, proprio per questo motivo, queste introduzioni non possono essere esaustive, bensì si tratta di «stimulating ways into new subjects», di stimoli per lo studio di vari temi.

2 Quella riguardante la letteratura francese è stata affidata a John D. LYONS, professore di Francese presso l'Università della Virginia e chevalier de la Légion d'Honneur. Gestire e dare unità e coerenza a circa mille anni di storia letteraria in 120 pagine non è impresa facile, e l'autore ha deciso, a tale scopo, di adottare un punto di vista in particolare, ossia quello del protagonista. Studiando i personaggi principali delle varie opere, i loro rapporti con la società e con gli altri, Lyons riesce a costruire un percorso letterario sostanzialmente unitario che parte dal Medioevo e giunge fino ai giorni nostri, analizzando, in ciascuno dei capitoli, il contesto storico-politico-sociale e l'atmosfera letteraria dell'epoca, soffermandosi a descrivere più dettagliatamente tre o quattro opere per ogni periodo. In aggiunta a questo, all'interno del libro sono presenti illustrazioni e brevi schede esplicative, in cui vengono riportati estratti di opere o poesie intere, oppure approfondimenti di determinati argomenti (come la differenza tra langue d'oc e langue d'oil, oppure l'importanza dei salotti letterari). 
3 Nel primo capitolo, per esempio, intitolato «Saints, werewolves, knights, and a poète maudit: allegiance and character in the Middle Ages» (pp. 5-17), l'autore colloca l'inizio della letteratura francese nel 1050 circa, anno di The Life of Saint Alexis; oltre a quest'opera vengono analizzati anche i Lais di Marie de France, la Chanson de Roland, Erec et Enide, Le roman de la Rose e le poesie di François Villon, considerato per l'appunto il primo poète maudit.

4 Il testo è composto di nove capitoli, corrispondenti alle varie epoche, all'interno dei quali lo studio delle opere dal punto di vista del protagonista permette sia di delineare una storia letteraria che evidenzi le innovazioni e le tematiche principali, sia di presentare i cambiamenti storico-sociali della Francia e il ruolo dell'individuo all'interno di essi, considerando, perciò, i personaggi principali di queste opere come una sorta di archetipi dell'umanità (senza dimenticare, però, i cambiamenti degli stessi protagonisti, il passaggio da eroe a anti-eroe e a "uomo comune", per esempio).

5 L'ultimo capitolo («French-speaking heroes without borders?», pp. 117-128) concerne i giorni nostri, con la difficoltà che questo può comportare, ma soprattutto pone in luce il problema dell'idea di letteratura francese nel suo rapportarsi con le letterature francofone. Cosa si intende per francophonie? ̇̀ oggi possibile identificare questo concetto come una categoria letteraria? Non è forse una nozione artificiale, razzista, instabile? Anche questo argomento è sintomatico della varietà, della vitalità e dell'importanza culturale di una letteratura come quella francese e di quella différence che Lyons loda. 